\title{
Perceptions of age in contemporary tech
}

\author{
Andrea Rosales ${ }^{I} \&$ Jakob Svensson ${ }^{\text {II }}$ \\ I Communication Network \& Social Changes, Universitat Oberta de Catalunya, Spain \\ II School of Arts and Communication, Malmö University, Sweden
}

\begin{abstract}
This article attends to age stereotypes and ageism in contemporary tech. In academia, little attention has been devoted to this topic. Therefore, we intend to initiate a discussion around ageism in tech by studying perceptions of age in the tech industry. Our study is based on interviews with 18 tech workers around the world of varying age. According to our interviewees, tech workers over 35 are considered old in the tech industry. Older tech workers are expected to become managers, thought to become less interested in new technology, and expected to have more challenges when learning new software. We also look at how tech workers of different age groups experience entrepreneurial values of the company as a playground, staying hungry, and changing the future with technology, and how these values influence their professional careers. We conclude that ageism is reinforced in contemporary tech through several stereotypes related to age.
\end{abstract}

Keywords: ageism, career, discrimination, tech culture, tech workers

\section{Introduction}

Stereotypes are social constructs commonly used in social interaction but that often lead to prejudices and discrimination (Sangrador, 1996). Ageism refers to discrimination based on age stereotypes (AGE Platform Europe, 2016). In this article, we consider ageism in tech, a topic that has largely been understudied in academia. Our study is based on 18 interviews with tech workers of varying age, working in large and small companies and as freelance, and there is also one student among the interviewees. At the time of the interviews, the participants were based in Bangalore, Barcelona, Berlin, Houston, Silicon Valley (including San Francisco and Oakland), and Tel Aviv. The focus of the interviews was on the past, present, and future of the respondents' professional careers and their perception of ageing and ageism in their work environments.

Tech culture has many different influences. It has its origins in the hippie counterculture of the 1960s, multidisciplinary military research centres, hacker culture, as well as in entrepreneurial enthusiasm (Turner, 2006; Svensson, forthcoming). Corporate tech is often described as influenced by a so-called Californian Ideology, combining the "free-wheeling spirit of the hippies and the entrepreneurial zeal of the yuppies" (Barbrook \& Cameron, 1996: 45). A common thread is a modern belief in being at the

Rosales, A., \& Svensson, L. (2021). Perceptions of age in contemporary tech Nordicom Review, 41(1), 79-92. https://doi.org/10.2478/nor-2021-0021 
forefront, a belief on changing the world, being bold and disruptive, and also having optimism about what technology can achieve - values which can be connoted to youth. Research within the social sciences has shown that contemporary digital technologies embed commercial interests (Zuboff, 2019), corporate culture (Kunda, 2006), as well as hacker values (Levy, 2010).

Such studies underline the importance of approaching tech as non-neutral and socially constructed. It is humans who engineer these technologies; therefore, it is essential to attend to the people behind the platforms and digital technologies we use and find out more about who they are (Hill, 2019; Svensson, forthcoming). Today, the communication landscape in connected societies is centred around digital technologies, with Silicon Valley constructing itself as the centre of a larger progressive movement, a link to the future in which digital technologies imply a better quality of life for all (Darrah, 2001). Kittler (in Peters, 2015) therefore labelled tech workers (or programmers) as "engineers of being", treating them (rather than philosophers) as history's most important actors. Much of what comes to pass as important in mediatised societies is based on what is produced and disseminated in media (Brooks \& Hébert, 2006); this is particularly the case with social media. Social media algorithms profoundly influence decisions about what to do, think, and buy (see Pasquale, 2015) - they create the world they claim to merely show. In journalism studies, it has been known for a long time that media not only report the news, they also make the news. If you then compare the number of studies on journalists - often with arguments of their power in democracies shaping our imaginations and worldviews - with the number of studies on tech workers, it becomes apparent that there is a gap that needs to be filled.

What do we know about tech workers and the potential consequences of their sociocultural belongings? Researchers have revealed structural racism in face recognition systems (Sandvig et al., 2016) and discriminatory behaviour reproduced by bots (Neff $\&$ Nagy, 2016) and connected this to the workers engineering these technologies. That tech culture is mainly white and male is well established. It seems the tech industry itself has accepted that there is a need for more women, people of colour, and different sexualities (Kamiran et al., 2012). There are many attempts to attract women to tech (Perna et al., 2009). During our research, some companies we visited proudly announced their support of local pride parades and used oversized signs to show that their offices are accessible to people with disabilities.

However, there is another axis of oppression to consider when studying discrimination in tech. Being engineered by mostly young programmers, tech products and services risk not taking into account the habits, uses, and interests of older people, thus reinforcing ageism (Rosales \& Fernández-Ardèvol, 2020). For example, in journalism and the popular press, the term "Silicon Valley Ageism" (see Wickre, 2017) has circulated, referring to extreme ageism in modern high tech. Nonetheless, scholarly work on the issue of ageism in tech is largely missing. We therefore pose the following question in this article: How do tech workers perceive age in contemporary tech industry, and how it is related to ageism? We depart from formulations of a distinct tech culture and theories of ageism. In the next section, we therefore consider tech culture in more detail. A section on ageism follows before we present our methodological considerations, results, and conclusions. 


\section{Background}

\section{Tech culture}

In her book, Technically Wrong, Wachter-Boettcher (2017) writes that tech is an insular, mono-culture where insiders bond over a shared belief in their own brilliance. She points out that tech culture is rather homogenous in terms of age, ethnicity, and gender; it is young and predominantly populated by men of Caucasian or Asian origin. However, it is also essential to acknowledge that tech today is the result of many influences, of which hacking is perhaps the most known. In an age of surveillance capitalism (see Zuboff, 2019), the leftist and countercultural origins of Silicon Valley and the personal computer are quickly forgotten. Turner (2006) argues that tech culture brings together two legacies: The Cold War military-industrial research culture and American counterculture. Tech is where industry and high science's technological and intellectual output meets Eastern religions, LSD mysticism, and the 1960s back-to-the-land movement. Certain aspects of these origins, such as freedom of information, individual empowerment, and realising the future through code, have been picked up by right-wing politicians (see Turner, 2006), coupling the capitalist logic of profit with an entrepreneurship and startup culture prevalent in tech today.

With its hippie and hacker history, teenage rebellion, and anti-authoritarianism, tech culture is oriented towards youth. Early hackers - populating the computer labs of established universities and later the garages of middle-class suburbia - were most often young prankster men. They showed a general dissatisfaction with the adult world, expressing teenage angst often rooted in science fiction's dystopian vision. It was about young people being comfortable with technology that could intimidate their elders (Thomas, 2002). Indeed, hacking could be seen as a space in which youth - particularly boys - could demonstrate mastery and autonomy and challenge parental and societal authority. The hacker's mastery of technology was often used for pranks at the expense of the adult world. The expression to do things "for the lulz" (derived from LOL - i.e., to laugh out loud) has a youthful rebellious feeling. Thomas (2002) thus considers such pranks as guerrilla warfare waged by boys against the adult world as well as an exercise in control.

The exclusive nature of access to university computer labs in the 1960s and 1970s undergirded popular depictions of programmers as nerds and computer geniuses (Thomas, 2002). Ensmenger (2015) connects programmers working together in dark spaces in front of computers - underdogs - with meritocracy ideals in which programming skills are favoured over titles and looks. That programmers are underdogs and tech culture is based on merits alone can be questioned, given the importance of male networks often founded in elite universities (Wachter-Boettcher, 2017). The hacker, and the later entrepreneur, are based on mostly white, male, Anglo-American networks (Turner, 2006).

In the 1980s, when more and more people had their own personal computers, the mostly male university culture of hacking was transformed into a more suburban youth culture (Thomas, 2002). Turner (2006) talks here about a group of predominantly white men who saw themselves as part of a creative, independent elite, bringing the world back into balance, combatting bureaucracy and authorities with information technology. This resonates in contemporary startup values, emphasising taking risks and believing in yourself (Svensson, forthcoming). 
Today, tech is marinated in entrepreneurship enthusiasm with slogans such as "invent the future" and "move fast and break things". This is particularly evident in large tech companies with services and food possibilities geared towards creating an atmosphere of play, loyalty, and flat hierarchies. Kunda (2006), in his ethnography of a tech company (researched in the 1980s), describes managers' attempts to generate enthusiasm and strong affiliation to the company through an enforced informality, openness, and flexibility. This is about combining paternal care with an open, informal, yet achievementoriented culture, mixing the playful with the semi-serious. Using images of belonging to a family, tech corporations underline that there should be no contradiction between personal and corporate goals (Kunda, 2006). This allure of offering opportunities for professional development, exciting work, relative autonomy, and fun, as well as a kind of formalised prescription of informality and semi-serious playfulness, still resonates in tech. No wonder tech is full of stories about young people devoting their whole lives to their companies and living their entire lives in the office. "It didn't look like a business whatsoever - it looked like a bunch of kids in their mid-twenties, you know, screwing around”, as Ayers (in Fisher, 2018: 279) described Google's early days. This kind of youthful entrepreneurialism has also spilt over to the rest of society and influences how identities are constructed today (see Bröckling, 2016).

\section{Ageism}

Tech culture is thus geared towards youth. This makes perceptions of age and ageism particularly important to study in contemporary tech industry. But what is meant with ageism? Ageism refers to discrimination based on age, which is typically negative and against older people (Ayalon \& Tesch-Römer, 2018). It builds on stereotypes: social constructs or shared ideas about the characteristics of a particular social category. Stereotypes are cognitive structures widely used in social interaction. Individuals are often judged based on their assigned category, which may lead to discrimination - for example, sexism, racism, or ageism (Sangrador, 1996) - and which disregards all diversities in such wide collectives.

Ageism is thus a particular form of discrimination in which individuals are dealt with and governed according to age-based stereotypes: what people should be doing, experiencing, or feeling depending on their age. Stereotypes, which often work unconsciously, contribute to discrimination by ignoring individuals' real habits, interests, and values (Ayalon \& Tesch-Römer, 2018). Beyond stereotypes, ageing is influenced by the process of growing old, which is shaped by life trajectories, and the cultural assumptions, expectations, and beliefs about ageing and about being old that shape human ageing (Ayalon \& Tesch-Römer, 2018). Thus, age stereotypes shape both the images that individuals have of themselves and the images that society has of different life stages and age-appropriate behaviour (Lagacé et al., 2015). These can be positive or negative, subtle or explicit (Ayalon \& Tesch-Römer, 2018), and may be directed at people of any age. However, the most common form is negative ageism towards the oldest individuals. It is argued that ageism is the most invisible form of discrimination (Ayalon \& TeschRömer, 2018) and that it could be more pervasive than sexism and racism (Officer \& de la Fuente-Núñez, 2018), as it is rooted in stereotypes that are widely accepted and little questioned in society. 
Age stereotypes also govern relationships in the workplace (McCann, 2012). With life expectancy around 80 in developed countries and retirement age between 62 and 67, older workers are most often identified as those aged 55 and over (McCann, 2012). Similarly, young workers are considered to be under 35, and middle-aged workers are somewhere in between. While young workers may be viewed as immature and in need of experience, older workers are perceived as less motivated, less enthusiastic, and more reluctant to learn new things. Such prejudices are based on the idea that physical and cognitive decline comes with ageing (McCann, 2012). Ageism is partly due to these widely accepted age stereotypes and partly due to the way in which contemporary Western welfare societies, through their retirement plans, have ousted older people from positions of power (McCann, 2012). After retirement age, people are conceived of as a burden to society. In this sense, ageism implies de-prioritisation, disregard, and even exclusion of older people (AGE Platform Europe, 2016). Age stereotypes thus govern relationships between individuals, society, and institutions, as well as products and services.

Concerning the use of digital technologies, a widespread idea is that older people are less interested in digital technologies (Durick et al., 2013). A digital divide reinforces this. Although older people consistently have lower technology adoption rates than the general public, this group is actually more digitally connected than ever (Eurostat, 2019). In addition, the global population is ageing. Thus, every year there are more older people and an increasing amount of them are using digital technologies. Older digital users may have different interests than younger users because personal values and interests change over the lifetime (Neugarten, 1996). Personal communication patterns and media use evolve as we grow older (Ling et. al., 2012). However, with tech culture geared towards youth, teenagers and young users are most often the imagined users when platforms and services are engineered and designed, risking the marginalisation of older users. It is therefore important to study perceptions of age and ageism among tech workers.

\section{Methodological considerations}

The question that we explore in this article is, how do tech workers perceive age in contemporary tech industry, and how it is related to ageism? To answer this, we conducted semi-structured interviews revolving around the past, present, and future of the participants' professional careers and their understanding of age in the tech industry. We asked them about their reasons for pursuing a tech career, their current situation, and their expectations about the future. The questions were directly related to age and ageism, and we invited participants to reflect on their own age and ageing in their work environments and whether or not their age perceptions could lead to discriminatory practices in the work environment. The interviews are linked to larger research projects that study people in tech, their imaginations, values, and background.

This article is based on 18 interviews. At the time of the interviews, participants were employed in tech companies or working as freelance programmers and, in one case, a student. We conducted interviews with tech workers employed by tech giants - such as Google, Facebook, and LinkedIn - as well as by smaller tech companies and startups. At the time of the study, these tech workers were based in Bangalore, Barcelona, Berlin, Houston, Silicon Valley (including Oakland and San Francisco), and Tel Aviv. While 
based in certain companies and in five different countries, the participants were nonetheless able to digress and discuss previous experiences in their professional careers, including work in other countries, cities, and companies. Their reported experiences may thus go beyond their current work situation. We interviewed fourteen men, three women, and one person who identified as non-binary. Four were in their 20 s, five in their 30 s, five in their 40s, and four in their 50s. All interviews were conducted in 2019 (see Table 1).

Table 1 Characteristics of interview participants

\begin{tabular}{lllllll}
\hline Gender & Age & City of interview & Origin & Occupational Status & Base & $\begin{array}{l}\text { Day of } \\
\text { interview } \\
\text { (2019) }\end{array}$ \\
\hline M & 40s & Berlin & Germany & Freelance & Berlin & 19 Jan. \\
M & 20s & Berlin & India & Tech company & Banglore & 19 Jan. \\
M & late 30s & Online & Israel & Freelance & Tel Aviv & 19 Jan. \\
F & late 30s & Berlin & Poland & Tech Student & Berlin & 19 Jan. \\
M & early 50s & Austin & USA & Freelance & Houston & 19 Mar. \\
M & early 30s & Austin & Mexico & Freelance & Houston & 19 Mar. \\
M & late 20s & Sillicon Valley & Denmark & Tech giant & Sillicon Valley & 19 Mar. \\
M & 50s & Sillicon Valley & USA & Tech giant & Sillicon Valley & 19 Mar. \\
M & 20s & Sillicon Valley & China & Tech giant & Sillicon Valley & 19 Mar. \\
F & 50s & Sillicon Valley & Lithuania & Entrepreneur & Sillicon Valley & 19 Mar. \\
NB & 50s & Sillicon Valley & USA & Tech company \& NGO & Sillicon Valley & 19 Mar. \\
M & 30s & Online & USA & Freelance \& NGO & Sillicon Valley & 19 April \\
M & 20s & Barcelona & Catalonia & Freelance & Barcelona & 19 June \\
M & early 30s & Barcelona & Catalonia & Entrepreneur & Barcelona & 19 June \\
M & early 30s & Barcelona & Catalonia & Tech Company & Barcelona & 19 Sept. \\
M & 40s & Barcelona & Peru & Tech Startup & Barcelona & 19 July \\
F & 40s & Barcelona & India & Tech Startup & Barcelona & 19 July \\
M & 40s & Barcelona & Mexico & Tech Company & Barcelona & 19 July \\
\hline
\end{tabular}

${ }^{\star}$ non-binary

We adopted a mixed recruitment strategy: snowballing personal contacts and using the LinkedIn and Meetup platforms. LinkedIn is a business and employment-oriented service that is mainly used for professional networking: "employers posting jobs and job seekers posting their CVs" (Wikipedia, n.d.-a). Meetup is a service used to organise online groups that host in-person events for people with similar interests (Wikipedia, n.d.-b). Both services are popular in the tech community, and it was relatively easy to get interviews. With a LinkedIn premium account, we were able to screen tech workers on the basis of their location and workplace and then send them a message. Through Meetup, we were able to target particular groups, such as the "Women who code the Silicon Valley" group, to diversify the sample. Hence, we cannot claim that our sample is representative with respect to gender, age, or ethnicity. Furthermore, we do recognise that the sample is rather small (while nonetheless quite diverse). Also, there are various categories of tech workers, with quite substantial differences between programmers, coders, developers, and project owners. Hence, even though we use the label tech worker as an umbrella term, this does not mean that a software engineer is exactly the same as a coder or a programmer or that 
the meaning of these titles resonates across contexts, countries, and locations. Still, our findings resonate across the interviews, and could thus form the basis of a larger and more representative study of tech workers. Another limitation of an interview-based study is that it relies on reflective accounts from participants. We consider this a minor limitation, as our questions centred around their expectations and experience of age. With this article, we hope to initiate a discussion around ageism in tech.

Interviews lasted between one and two hours and were conducted face to face or online. They were conducted in different languages, depending on the local context and the common language with the interviewees. We transcribed the interviews, and we each analysed our own interviews, highlighting any excerpts related to age or ageism. We then translated any excerpts from interviews not conducted in English into English, and conducted a joint analysis of themes cutting across the 18 interviews. The interview transcriptions were analysed vertically (as a single entity) and horizontally (theme-bytheme analysis across all 18 interviews). When quoting interviewees, we use labels such as "M20s, Barcelona" to identify the participant by their gender, age, and the city where they were interviewed.

\section{Results}

What is considered old in tech?

Ageism in tech is not new. In Fisher's (2018) book on the history of Silicon Valley, there are numerous examples of how youth-oriented tech culture is. This resonates decades later in our empirical material. In general, our interviewees described "older programmers" as those above 35 years old and young programmers as under 30 . In their descriptions, our interview participants identified themselves and their co-workers as either young or old, leaving no space for middle-aged tech workers. This was illustrated in an interview with a young programmer of Chinese origin when asked if there were any older people in his team. He answered no by referring to "older" as those over 40 .

Our interview participants reported that most of the tech workers in their workplaces are under 30. For example, in an interview with an Israeli entrepreneur, he described his team as young and that he is the oldest with his 38 years. Participants also put forward an argument that the overwhelming presence of young people in tech companies is related to a generational issue. A male in his 30 s in Silicon Valley, who considers himself as "older", explained that the majority presence of young programmers is due to computer engineering not being common in universities when he was young.

This shared idea that most tech workers are young has moved tech towards normalising co-workers' expected age as young. Some of our interviewees referred to rumours in Silicon Valley that there is an unspoken rule that one cannot get hired unless they are under 35, suggesting discriminatory practices against "older" tech workers. A female manager in her 50s in Silicon Valley, for example, explicitly stated that if you are over 50 (and white and male), it is "impossible" to find a job in Silicon Valley. Another participant in his early 30 s even questioned whether he would be able to program when he was older:

I have thought to myself, what will happen when I end up outside this group, that is, when I get older, 50 maybe? Will I still program then? Will it be normal to 
be a programmer when I am 50? I don't know really because today it is not that usual. (M30s, Austin)

From our sample, we can thus conclude that age is either perceived as young or old, and the dividing line is between 30 and 35 in terms of when you transition from young to old in contemporary tech industry. In the next section, we present what interviewees reported as perceived consequences of these expectations of age.

\section{Age expectations in tech}

When it comes to age expectations, the younger tech workers reported working in startup companies, while the more experienced participants were expected to get positions in more consolidated companies, where there were better salaries and working conditions could be adjusted to outside work matters, such as having a family. This difference is illustrated in the excerpt below:

This company is seven years old. When it started, all the people that came in were super young. An older profile means someone with a lot of experience, and the salaries don't match. (M30s, Barcelona)

According to our participants, salaries are lower and working conditions worse in companies where most of the workers were young. Younger tech workers are expected to be inexperienced and need to work more hours to acquire the skills required or to be more productive. Conversely, older tech workers are assumed to be experts and often expected to go into management positions with more responsibility, such as project leaders, researchers, managers, and so on. This kind of linear progression from coding to management is not desired by all tech workers, according to our interviewees, either because they switched to a programming career later in life, or simply because not all of them were interested in management positions, as in the excerpt below:

My problem is that after this position, the next step is managing people [...] I don't want to quit programming to manage people. (M30s, Barcelona)

If this imagined path from coding to management is not followed, it can create problems, as older workers are expected to manage younger workers - not the other way around. When this is not the case - when an older worker is lower down in the workplace hierarchy - the assumption is that this would be hard to accept, both for the "older programmer" and the "younger manager". This is illustrated in the excerpts below from our interviews with female tech workers in both Silicon Valley and Barcelona:

So, the managers themselves are uncomfortable managing older people [...] my managers were never younger than me so [...] and the guys that I work with who are younger than me, they don't feel intimidated. (F50s, Silicon Valley)

I was looking for a junior position as an older person. They have to make the younger person tell me what to do. That person might feel uncomfortable. Maybe I would feel uncomfortable too; maybe after a while, I would say, who are you to tell me what I have to do, you stupid kid. (F40s, Barcelona)

Our findings reveal that it is also expected that older tech workers are less interested in technology and will not come up with "anything new, modern or exiting", as one par- 
ticipant put it. An idea exists that older workers are not really up to date with the latest technologies and their potential. A male programmer in Barcelona in his 20s described this quite bluntly: "These managers in their 40s, the problem is that they don't understand the real potential of this technology". This idea also spilled over in comments on the imagined user of the kind of tech products and services our participants work on. There is a common assumption that most users are young, and hence that the design and development of products and services is best handled by young tech workers. When we asked why there were so many young people at her company, a non-binary tech worker in her (her preferred pronoun) 50s in Silicon Valley explained that "it is because the average age of our users is younger, so it is more market-related than anything else". However, at least in Europe, tech is used by people of all ages (see Eurostat, 2019). By focusing on younger users, the particular interests of older users risk being neglected.

There is also an expectation of older tech workers being less interested and inclined to learn new things and adapt to changes (so-called cognitive decline, see McCann, 2012). A young male programmer in Silicon Valley stated that the Bay Area is populated by young people "because things are evolving and old people have trouble keeping up... I'm not saying they cannot, but sometimes they have trouble". A female programming student in her late 30s in Berlin seconded this, complaining that it is "very hard to keep being relevant, you know... you should not always be in your comfort zone because then you are not relevant anymore". This was further underlined by the non-binary tech worker in Silicon Valley:

Good older developers who are great can keep up, but they probably can't keep up with the pace of change. It also depends on where you are. So, I see a tendency for the bad or mediocre [programmers] [...], they will just continue with the ancient but necessary technology, make a living out of that and get left behind. (NB50s, Silicon Valley)

Among our participants, there was an idea that people willing to enter the tech industry are not able to assimilate the required skills if they are "old". A tech worker in his $40 \mathrm{~s}$ in Barcelona linked the motivation to learn new skills with age in this manner, that older tech workers were not as willing to embrace the role of a beginner, as exemplified in the excerpt below:

Getting into the tech industry as an older person is incredibly difficult given the number of young people... it is a lot of learning, and it takes a lot of years, and adults are generally not willing to be beginners in that way. (M30s, Silicon Valley)

Some interviewees perceived getting older as a potential problem in terms of processing information. The interview excerpt below shows a freelance programmer's argument for why he had chosen to stay freelance:

I don't know if I can continue my work forever. I like my job, but I don't know if my brain can process all this information or if I'll be able to sit and program for 10 hours a day when I get older. When I get home after a long workday, I'm braindead. (M40s, Berlin)

This resonated with the female programming student in Berlin attempting to change her career and finally pursue her dream of becoming a programmer. But in her late 30 s, she felt old: 
I need more time to learn, to spend time at home. Sometimes I'm there until 2 am [...] I just feel the breath of my younger colleagues behind me, so [...] it is not easy $[\ldots]$ I have two pretty young colleagues [...], and they are faster, not always as good as they should be, but fast, and sometimes their experience is not so good $[\ldots]$ it is not easy to stay motivated. (F30s, Berlin)

There thus seems to be a continuous trade-off between being in a comfortable position and continuing to learn and work as hard as is expected in contemporary tech. In some cases, our participants found a niche, for example, working with specific technologies such as old programming languages that might still be used in some areas (as was the case with our freelance programmer in Berlin).

\section{Tech as a work environment in relation to age}

As previously discussed, tech's roots in hacker culture - its entrepreneurship and startup values - impact how work in the tech industry is conducted. Tech workers are expected to live for their company and work long hours, and the team is supposed to be their family. That this becomes problematic when, or if, starting a family became obvious in our interviews. A tech worker in his 40s in Barcelona, for example, explained that he wanted to work in a company "close to home, in a company without any financial struggles, to have a balance between quality of life and stress, and to have the possibility of working remotely". Influenced by startup and entrepreneurship values, contemporary tech industry emphasises the importance of being hungry and mobile, and it expects workers to devote their whole lives to the company. This is illustrated in the excerpt below:

The Bay Area is where you live for a little while, and then you cash out. People are here for the experience, and that is why you don't see a lot of old people; the old people you see here are the rich ones. (M30s, Silicon Valley)

The norm of being young and enthusiastic (especially in startups) was illustrated by the Israeli entrepreneur when asked whether he had ever experienced ageism in tech. He told us a story about how he talked to an investor about his partner, who was 27 , and he portrayed him as "super passionate, quick at coding", and connected this to his younger age. The investor really liked that part of his description. That was the first time he had experienced ageism, he told us. This connection between youth and startups values was further underlined by an entrepreneur in Barcelona:

Young people are more open to this aspect of startups, working endless hours, devoting all the passion that the product requires; an older person probably has a family and different priorities. (M32, Barcelona)

Hence, while young tech workers are expected to work longer hours, they are at the same time perceived as less experienced, less productive, but nonetheless willing to learn, pick up new things, and devote their time to their work. Conversely, older tech workers are portrayed as slower, less connected to their work, and more focused on personal and family issues, and hence less attractive as co-workers. "When people get older, they value other things in their life", such as their families, and "maybe they don't put a lot of effort into their work", as the Israeli entrepreneur put it. 
This is also connected to the way in which tech companies often provide on-site entertainment, games, food, and drinks meant to encourage team-building. When visiting some of the headquarters of our interviewees' workplaces, we were blown away by the scale of the place and the number of free services, exquisite art and delicious food available to us without having to open our wallets once. We saw environmentally conscious services like bike-repair shops, an in-house smokery for Texan barbecue, and art workshops where tech workers could make, for example, their own pins or posters. This underlines the way in which the tech workplace almost becomes like a playground and a space for sociality where workers are expected to spend their whole day and also the evening. This often fits better with a young lifestyle, or at least for tech workers who have no family responsibilities; they are the ones who have a greater incentive and possibility to take advantage of these services. For example, a male programmer in his 30s in Barcelona described how there "are juices, and fruit and games", but how he nonetheless “would like to work from home [and don't] want to have to work extra hours". Another Barcelona tech worker, a bit older, put it in the following manner:

I know it means bad salaries and fewer benefits. There is beer, and some stay on after work to have a few beers; I go home to my family. The time I spend playing table football, I would rather be at home. (M40s, Barcelona)

Hence, workers who prefer not to use these on-site resources risk being marginalised in their teams. A corporate culture that promotes team-building through a young lifestyle (see also Kunda, 2006), risks deprioritising, disregarding, and excluding older workers.

\section{Conclusion}

In this article, we studied how tech workers perceive age in contemporary tech industry, and how this is related to ageism. According to our interviews, young tech workers are under 30, and old tech workers are over 35. Hence, the label "older" is pushed back by 20 years compared to other professions (see McCann, 2012) and middle-age is erased almost altogether in contemporary tech. These perceptions about "young" and "old" are coupled with expectations of older tech workers being less passionate, more connected to their own families than the company they work for, having a harder time processing information and picking up new things, and being less interested in technology in general. Older tech workers are not expected to understand or be as interested in technology as younger tech workers and are perceived as less focused on their professional goals, making them less attractive co-workers.

Furthermore, corporate programmes present workplaces as playgrounds, with onsite benefits and team-building programmes, underlining entrepreneurship values of the company as a family - the family - conflating personal life with corporate goals. Tech is a culture that challenges the tech worker to "change the future, move fast and break things" (Svensson, forthcoming). This drive to stay hungry and change the world (Levy, 2010) - to disrupt old businesses (Turner, 2006) - is more closely identified with a tireless young worker than a family-oriented worker with the obligation of picking up their kids from kindergarten at 5 pm every day. The devoted passion for work and the workplace more often caters to a younger tech worker, and tech corporations thus risk disregarding or even excluding "older" tech workers. 
Age stereotypes often work unconsciously. The tech workers we met were most often not consciously excluding their "older" teammates. Nonetheless, the age stereotypes that emerged in our interviews are likely to have a bearing on corporate culture as well as personal expectations of tech workers, and consequently their own professional careers. "Young" tech workers' passion for programming could be exploited by corporations that push them to work overtime. Conversely, "old" tech workers still working in tech-based companies are not expected to be as interested and quick in picking up new programming languages, for example.

Representation matters, and our material revealed an awareness of how the lack of diversity concerning gender and ethnicity among programmers has an influence on the bias of tech products and services (see also Sandvig et al., 2016; O'Neil, 2016). Still, most tech workers we interviewed believe that, in the particular products and services they work on, the lack of diversity has no direct influence. However, as (Rosales \& Fernández-Ardèvol, 2020) has shown, tech products and services are not designed for users with lower digital literacy, such as older users. In this way, contemporary tech reinforces ageism. Moreover, tech products and services miss opportunities to address interests that may be uncommon among young users - not least also as life expectancy in connected societies is on the rise. As digital tech products and services become increasingly ubiquitous, and older users more connected and skilled, ageism in tech will become increasingly problematic. Older people already are, and will continue to be, users of technology - and increasingly so. If the goal is to offer services to as many as possible, people of all ages should be included in the design and engineering of tech products and services, in order to have the habits, interest, and values of all catered to.

\section{Funding and acknowledgments}

We would like to thank the Swedish Research Council and The Spanish Ministry of Science, Innovation, and Universities (grant IJCI-2017-32162) for sponsoring part of this research, as well as the Nordicom staff and reviewers for helpful comments on this paper.

\section{References}

AGE Platform Europe. (2016). AGE platform Europe position on structural ageism. https://www.age-platform. eu/publications/age-position-structural-ageism

Ayalon, L., \& Tesch-Römer, C. (Eds.). (2018). Contemporary perspectives on ageism. Springer Open. https:// doi.org/10.1007/978-3-319-73820-8

Barbrook, R., \& Cameron, A. (1996). The Californian ideology. Science as Culture, 6(1), 44-72. https://doi. org/10.1080/09505439609526455

Bröckling, U. (2016). The entrepreneurial self: Fabricating a new type of subject. London: Sage. https://doi. org/10.4135/9781473921283

Brooks, D. E., \& Hébert, L. P. (2006). Gender, race, and media representation. In B. J. Dow, \& J. T. Wood (Eds.), The Sage handbook of gender and communication (pp. 297-318). Thousand Oaks, California: Sage. https://doi.org/10.4135/9781412976053.n16

Darrah, C. N. (2001). Techno-missionaries doing good at the center. Anthropology of Work Review, 22(1), 4-7. https://doi.org/10.1525/awr.2001.22.1.4

Durick, J., Robertson, T., Brereton, M., Vetere, F., \& Nansen, B. (2013). Dispelling ageing myths in technology design [Conference proceedings]. Australian Computer-Human Interaction Conference (OzCHI 2013) (pp. 467-476). https://doi.org/10.1145/2541016.2541040

Ensmenger, N. (2015). "Beards, sandals, and other signs of rugged individualism": Masculine culture within the computing professions. Osiris, 30(1), 38-65. https://doi.org/10.1086/682955

Eurostat. (2019). Internet use in the last 3 months by Individuals [isoc_ci_ifp_iu]. 2018 data (Last update: 03-07-2019).http://appsso.eurostat.ec.europa.eu/nui/show.do?dataset=isoc_ci_ifp_iu\&lang=en 
Fisher, A. (2018). Valley of Genius, the uncensored history of sillicon valley (As told by the hackers, founders and freaks who made it boom). New York: Hachette Book Group.

Hill, D. W. (2019). The injuries of platform logistics. Media, Culture and Society, 42(4), 521-536. https:// doi.org/10.1177/0163443719861840

Kamiran, F., Karim, A., Verwer, S., \& Goudriaan, H. (2012). Classifying socially sensitive data without discrimination: An analysis of a crime suspect dataset [Conference Proceedings]. 12th IEEE International Conference on Data Mining Workshops, ICDMW 2012 (pp. 370-377). https://doi.org/10.1109/ ICDMW.2012.117

Kunda, G. (2006). Engineering culture, control and commitment in a high-tech corporation. Philadelphia: Temple University Press.

Lagacé, M., Charmarkeh, H., Laplante, J., \& Tanguay, A. (2015). How ageism contributes to the second level digital divide: The case of Canadian seniors. Journal of Technologies and Human Usability, 11(4), 1-13. https://doi.org/10.18848/2381-9227/CGP/v11i04/56439.

Levy, S. (2010). Geek power: Steven Levy revisits tech titans, hackers, idealists. Wired. https://www.wired. com/2010/04/ff-hackers/

Ling, R., Bertel, T. F., \& Sundsøy, P. R. (2012). The socio-demographics of texting: An analysis of traffic data. New Media \& Society, 14(2), 281-298. https://doi.org/10.1177/1461444811412711

McCann, R. M. (2012). Ageism at work: The role of communication in a changing workplace. Girona, Spain: Aresta.

Neff, G., \& Nagy, P. (2016). Talking to bots: Symbiotic agency and the case of Tay. International Journal of Communication, 10, 4915-4931.

Neugarten, B. L. (1996). The young-old and the age-irrelevant society. In B. L.Neugarten, \& D. A. Neugarten (Eds.), The meanings of age: Selected papers of Bernice L. Neugarten (pp. 47-55). Chicago: The University of Chicago Press. https://doi.org/10.1093/geronj/42.5.519

O’Neil, C. (2016). Weapons of math destruction: How Big Data increases inequality and threatens democracy. New York: Crown Books.

Officer, A., \& de la Fuente-Núñez, V. (2018). A global campaign to combat ageism. Bulletin of the World Health Organization, 96(4), 295-296. https://doi.org/10.2471/BLT.17.202424

Pasquale, F. (2015). The black box society. Cambridge, Massachusetts: Harvard University Press. https://doi. org/10.4159/harvard.9780674736061

Perna, L., Lundy-Wagner, V., Drezner, N. D., Gasman, M., Yoon, S., Bose, E., \& Gary, S. (2009). The contribution of HBCUS to the preparation of African American women for stem careers: A case study. Research in Higher Education, 50(1), 1-23. https://doi.org/10.1007/s11162-008-9110-y

Peters, J. D. (2015). The marvelous clouds: Toward a philosophy of elemental media. The Chicago: University of Chicago Press. https://press.uchicago.edu/ucp/books/book/chicago/M/bo20069392.html

Rosales, A., \& Fernández-Ardèvol, M. (2020). Ageism in the era of digital platforms. Convergence, 26(5-6), 1074-1087. https://doi.org/10.1177/1354856520930905

Sandvig, C., Hamilton, K., Karahalios, K., \& Langbort, C. (2016). Automation, Algorithms, and Politics | When the algorithm itself is a racist: Diagnosing ethical harm in the basic components of software. International Journal of Communication, 10, 4972-4990. https://ijoc.org/index.php/ijoc/article/view/6182

Sangrador, J. L. (1996). Identidades, actitudes y estereotipos en la España de las autonomías [Identities, attitudes and stereotypes in the Spain of the autonomies]. Madrid: Centro de Investigaciones Sociologicas.

Svensson, J. (forthcoming). Wizards of the web: An outsider's journey into tech culture, programming, and the logics of mathemagics. Gothenburg: Nordicom, University of Gothenburg.

Thomas, D. (2002). Hacker culture. Minneapolis, Minnesota: University of Minnesota Press.

Turner, F. (2006). How digital technology found utopian ideology: Lessons from the first hackers' conference. In D. Silver, \& A. Massanari (Eds.), Critical cyberculture studies (pp. 257-269). New York: New York University Press.

Wachter-Boettcher, S. (2017). Technically wrong: Sexist apps, biased algorithms, and other threats of toxic tech. New York: W. W. Norton \& Company.

Wickre, K. (2017). Surviving as an old in the tech world. Wired. https://www.wired.com/story/surviving-asan-old-in-the-tech-world/

Wikipedia. (n.d.-a). LinkedIn. Retrieved November 28, 2019, from https://en.wikipedia.org/wiki/LinkedIn Wikipedia. (n.d.-b). Meetup. Retrieved November 28, 2019, from https://en.wikipedia.org/wiki/Meetup

Zuboff, S. (2019). The age of surveillance capitalism: The fight for a human future at the new frontier of power. New York: Hatchette.

(C) 2021 Nordicom and respective authors. This is an Open Access work licensed under the terms of the Creative Commons Attribution-NonCommercial-NoDerivatives 4.0 International Public licence (CC BY-NC-ND 4.0). To view a copy of the licence, visit https://creativecommons.org/ licenses/by-nc-nd/4.0/ 